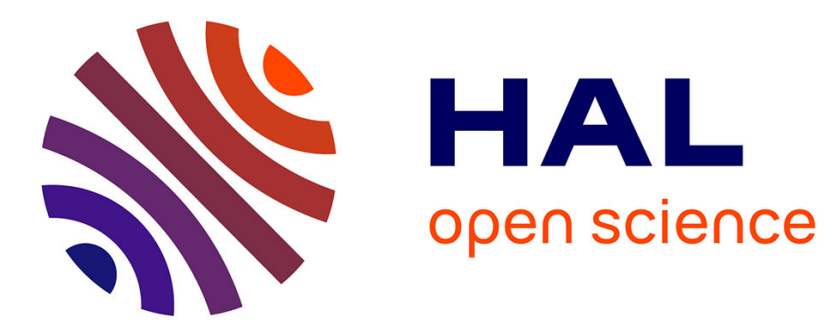

\title{
Underground ancient mine work ventilation modeling
}

Christophe Ars, Joseph Gauthier, Nicolas Florsch

\section{To cite this version:}

Christophe Ars, Joseph Gauthier, Nicolas Florsch. Underground ancient mine work ventilation modeling. Journal of Archaeological Science: Reports, 2021, 37, pp.102805. 10.1016/j.jasrep.2021.102805 . hal-03511898

\section{HAL Id: hal-03511898 \\ https://hal.science/hal-03511898}

Submitted on 5 Jan 2022

HAL is a multi-disciplinary open access archive for the deposit and dissemination of scientific research documents, whether they are published or not. The documents may come from teaching and research institutions in France or abroad, or from public or private research centers.
L'archive ouverte pluridisciplinaire HAL, est destinée au dépôt et à la diffusion de documents scientifiques de niveau recherche, publiés ou non, émanant des établissements d'enseignement et de recherche français ou étrangers, des laboratoires publics ou privés. 


\section{Underground ancient mine work ventilation modeling}

\section{Christophe Ars ${ }^{\mathrm{a}}$, Joseph Gauthier ${ }^{\mathrm{b}^{*}}$, Nicolas Florsch}

a Archaeologist. Engineer from ENSMA (Bordeaux)

b CNRS, UMR 6249 Chrono-environnement, Besançon

c Sorbonne Université, UMI 209 UMMISCO and UMR 7619 METIS

${ }^{(*)}$ Corresponding author ${ }^{1}$

\section{Abstract}

Excavations at the Giro mine located in the commune of Sainte-Marie-aux-Mines (France) have revealed a metallic and cylindrical artifact that resembles a connecting element for wooden duct sections. Early modern literature, and especially De Re Metallica, mention such technologies intended in particular to force the ventilation of otherwise unbreathable underground mines. The connecting element was found in a gallery leading to a stope of which ventilation seems problematic. The numerical simulation of the air flow in the tunnel makes it possible to test the ventilation hypotheses formulated from archaeological data. These simulations are performed with OpenFOAM, a free and open source software for computational fluid dynamics (CFD). Simulating not only the air flow, but also the heat and $\mathrm{CO}_{2}$ production of five miners at work highlights the need to force venting in the underground with a ventilation system. It also appears that the construction of scaffolding in the stope can fulfill the double function of facilitating circulation and improving ventilation. This first quantitative approach to one of the main obstacles to mining offers a new method for testing the solutions implemented by miners of the past.



1 Corresponding author: Joseph GAUTHIER, CNRS UMR 6249 Chrono-environnement / Université de Franche-Comté / 16 route de Gray / F-25000 Besançon / joseph.gauthier@univ-fcomte.fr / +33381666127 


\section{Keywords}

Mining archaeology / Ventilation system / Numerical modelling / Computational fluid dynamics / Breathability / Sainte-Marie-aux-Mines

\section{Introduction}

Mining activities have long been - and still are - an essential source of wealth for sovereign states and principalities. The extraction of raw materials, in particular those presenting strategic values through their industrial use or for minting money, has always involved considerable investments. Access to and successful extraction of mines allow a state to position itself among its neighbors as on a global scale. From the $5^{\text {th }}$ century BC Laurion mines in Greece to the modern-time mines of Potosi, those who hold rich minerals hold the wealth and that's that.

Visiting an underground set up dating from before the invention of explosives immediately immerses the researcher in the extraordinary scale of money and man-time investments dedicated to this activity. Although less visible than pyramids, the underground work, once added up, is beyond understanding: there are hundreds of kilometers of galleries, carved with a hammer and an iron gad or by the use of fire-setting.

Although the extraction itself is the main and certainly the most visible part of the investment, dewatering and ventilation come second only in terms of expenditure. The latter aspects must be taken into account before even thinking about ore dressing and metallurgical transformations that follow after the mining work. However, these workstations are not always present, depending on the possibilities the field offers, and can often be bypassed or in any case facilitated in mountainous areas.

Ventilation, along with dewatering, is a major concern in mining. Sufficient fresh air must be provided for the miners who work in the galleries that are sometimes confined and far from the surface. Nowadays, complex mechanical ventilation systems (and, thanks to electric fans, forced ventilation) respond to this demand but the question remains open for the mines of Antiquity and the Middle Ages when men did not benefit from these technologies.

A distinction must be made between mountainous and lowland areas. In the mountains, the miner tries to establish openings at different altitudes as soon as possible (Grandemange, 1988) or to use false ceiling systems (Florsch and ASEPAM, 1995). When such installations are not implemented (in particular at the start of drilling), air renewal is not naturally ensured beyond fifty meters in a gallery, as has been shown by Florsch et al. (2002).

In the plains, where galleries are systematically located at a lower altitude than the surface itself, the use of wind traps was frequent, as evidenced by various sources (starting with those of Agricola, 1556). The problem is most critical in summer: the cool air stagnates in underground works. This cold air is also denser. Artificial ventilation may also be established by using multiple wells. A fire at the base of such a shaft creates an ascending air flow and thus allows for fresh air to be sucked in through the other 
shafts. This very probably explains the particular geometry seen, for example, in the Carolingian mining sector of Melle in western France (Téreygeol, 2014; Bonnamour and Marconnet, 2014).

Existing literature has already dealt with the matter of ventilation in galleries and shafts. An unprocessed issue is definitely challenging for mining archaeologists. The ventilation of the various kinds of stopes, especially those relative to the veins that have been excavated and where the miners were digging, is such an issue. These areas most often follow geological fracturing, developing narrow vertical to sub-vertical void volumes. They can extend over several dozens of meters in two directions with perpendicular thicknesses of a few decimeters to several meters.

These underground work areas can be far from the mine's entrance, and drilling at another altitude only to create a natural air flow is most often complicated and costly, at least at the beginning. In that case, the issue of ventilation for air renewal is crucial. The only solution is to provide the mine with a system for conveying fresh air to the bottom, and/or for evacuating stale air.

Here we study the functioning of a ventilation system in complex mining volumes of the excavated vein zone type such as we meet in the Vosges mountains.

\section{From the discovery of a ventilation duct to the exploration of an ancient mine ventilation system}

The discovery of a metallic seal and a wooden ducting artifact in the Giro mine at Sainte-Marie-auxMines (Alsace, France) motivated us to begin this study.

\subsection{A horizontal duct discovered at Sainte-Marie-aux-Mines}

The Giro mine is located in the heart of the Altenberg, which is a mining sector continuously exploited since the end of the Carolingian period to the Thirty Years War (Gauthier and al., 2015). The district, and this claim in particular, are primarily mineralised in galena, then in gray copper, embedded in a gangue of quartz and siderite. The vein system is surrounded by gneisses with various lithologies. Giro mine has been very recently explored for the first time thanks to an archaeological excavation program since its rediscovery in 2016. Observing the digging directions and intersections of galleries lead to the identification of three phases of exploitation, for which currently no absolute date can be given. One can nonetheless attribute the first phase to the central Middle Ages $\left(10^{\text {th }}-12^{\text {th }}\right.$ centuries $)$, the second to the $15^{\text {th }}-16^{\text {th }}$ centuries, and the last to the $17^{\text {th }}-18^{\text {th }}$ centuries (Gauthier and Hergault, 2019). The area where the remains of a wooden duct were found corresponds to a gallery along a vein mainly exploited during the $15^{\text {th }}-16^{\text {th }}$ centuries (figure 1). The original entrance to this gallery is still unknown since colluvions has halted current progression (it is nowadays accessed via a modern gallery from below). Stopes were dug upwards and downwards from the gallery. All the underground networks related to this $15^{\text {th }}-16^{\text {th }}$ c. phase of activity were dug with hand tools. No trace of fire-setting has been observed. The issue of smoke does not have to be taken in consideration. 


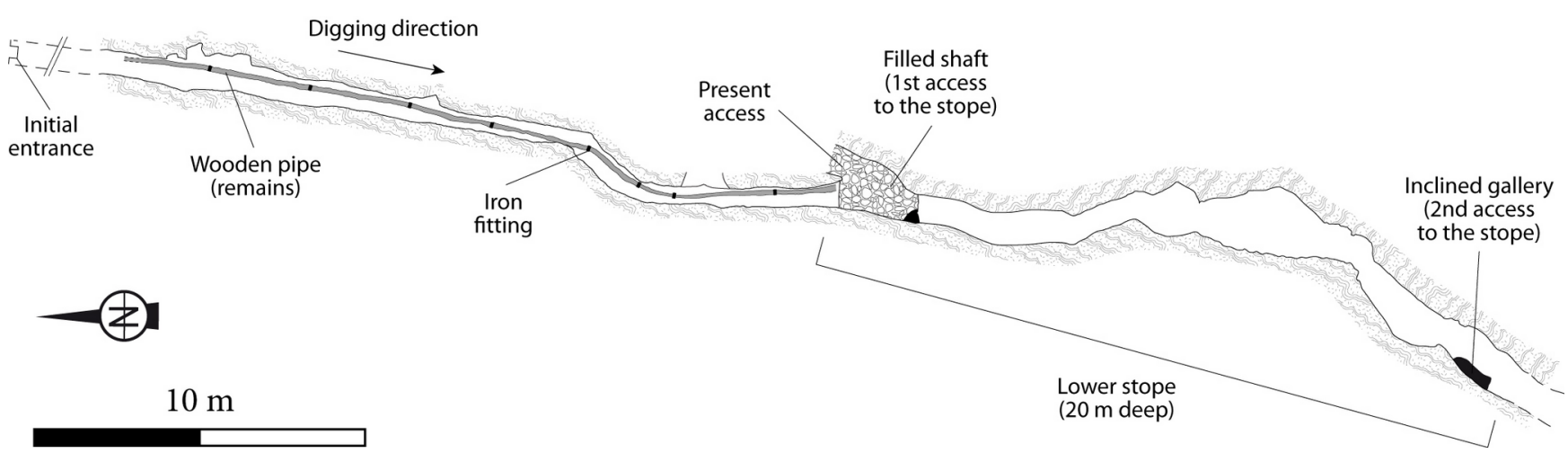

Figure 1: Projected horizontal plan of a part of the level 610 of the Giro mine, showing the location of duct remains and the ways to the lower stope.

The excavation of the area located between the entrance and the first descending stope permitted to discover the remains of a wooden pipe lying on the gallery floor. The remains of this facility consist of a streak of decomposed wood punctuated by metal rings found still in place. The pipe can be followed for over $22.5 \mathrm{~m}$. Eight iron pipe sealing joints were discovered. The interval between two connecting pieces stays constant $(3.05 \mathrm{~m})$ except upon turning a corner. The fittings are then positioned closer to each other to adapt the curvature of the pipe to the gallery. The duct ends upon reaching a filled shaft that communicates with a lower stope. It is reached by following another decline that leads into the gallery about thirty meters from said shaft.

The discovered fittings have the shape of iron rings with an approximate internal diameter of 7-8 $\mathrm{cm}$. (figure 2). The diameter cannot be measured accurately due to the state of alteration of the artifacts. The ring is about $4 \mathrm{~cm}$ wide, and has two stops around its outer periphery, in between which there is a $1 \mathrm{~cm}$ wide. We can link these artifacts to those represented on one of the engravings in book 6 of $\mathrm{De} R e$ Metallica. The component was used to join the different parts of the pipe by forcing the wood onto each side until it reached the stopes. This system seals the connecting pipes. 

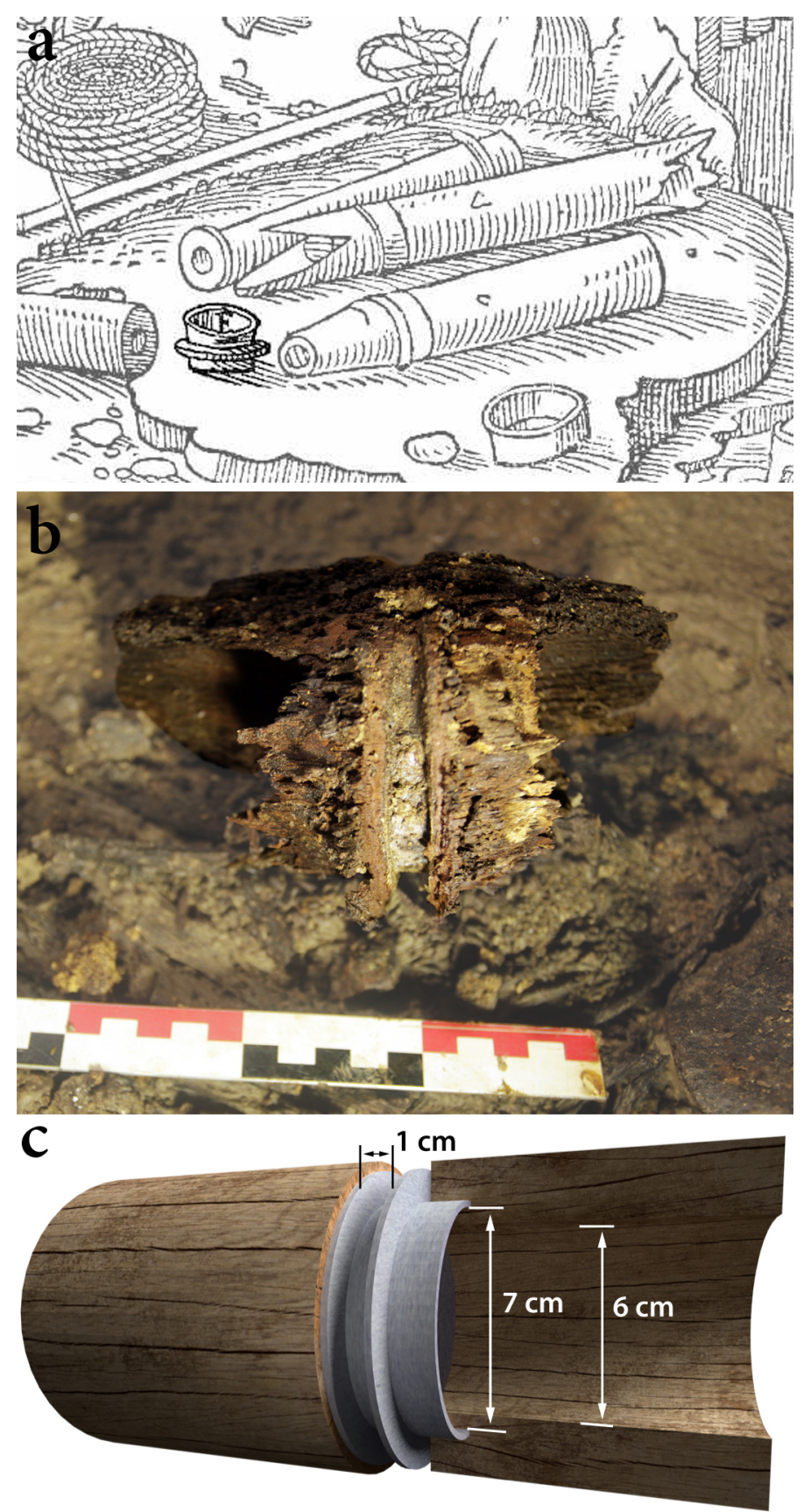

Figure 2: (a) De Re Metallica (1556), book 6, fig. 178. The metallic fitting can be seen down left; (b) One of the iron fitting found in the Giro mine; (c) Reconstruction of the fitting connecting two sections of the wooden pipe.

However, the graphical representation of the seal in Agricola concerns the hydraulics system, and more particularly a sealing of a pump body. Its diameter is larger, while the diameter of the pipe found in the Giro mine would not allow it to be used for water drainage. It might also be noted that Agricola never represents a pipe used for nearly horizontal drainage, but always open channels. Equipping a gallery with a pipe when water can naturally flow on its floor would not make sense either. The remains found thus correspond to a duct intended to transport air. How such a system was set up on the floor of a gallery is explained and shown a few pages later, still in book 6 of De Re Metallica (figure 3). We 
therefore propose to interpret the presence of this pipe as evidence of a system for conveying fresh air from the outside to the lower stopes and galleries. It therefore had to be connected to a gear located at the mine's entrance, such as the bellows depicted in the engraving of the Saxon doctor's book.

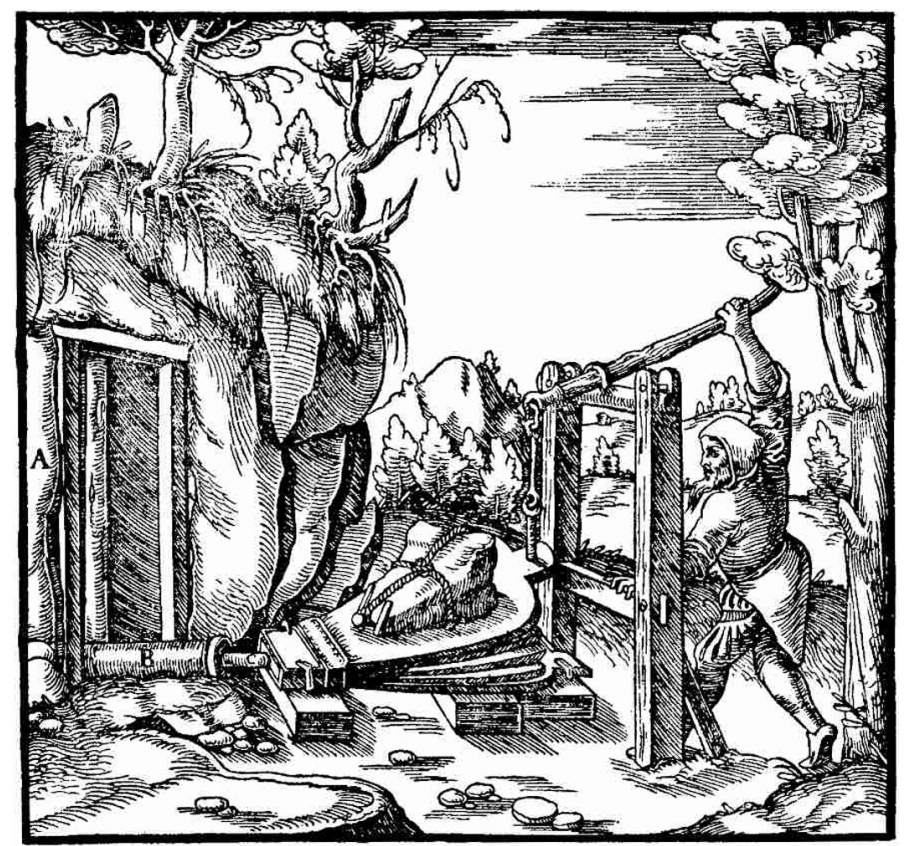

Figure 3: De Re Metallica (1556), book 6, fig. 209. The ventilation system consists of one gear located at the mine's entrance connected to a conduct set on the floor and entering the gallery.

To validate this hypothesis of forced ventilation actuated by external bellows, it would be best to reconstruct this system. Since this is not possible physically, numerical simulation of the air flow in the mine can be used to test and validate different assumptions. This approach resembles experimental archaeology but in a context where life-size experimentation would be very difficult to carry out. The numerical simulation approach is a computational substitute for reality.

\subsection{Numerical model implementation}

In the same way that the benchmark reproduces a device or a process to check its own effectivness, one must build a numerical model that represents the mine and its ventilation system. It is based on a simplified geometry of the gallery and includes five miners working there.

\subsubsection{Model geometry}

Modeling involves a simplified representation of the mine from a geometric point of view. It would in fact be impossible to simulate the air flow taking into account the reality of the mine down to the smallest roughness of the wall. Taking into account wall asperities would have the same effect as changing slightly the widths of the stope, and would not lead to significant changes in the modelling. However, the model retains the general geometrical features that influence the air flow, and obtained results are reliable in terms of scientific conclusions. 
The model involves several parts:

1) The underground route which is shown in figure 4 is made up of a $60 \mathrm{~m}$ long and $2 \mathrm{~m}$ high gallery, a vertical extraction site $20 \mathrm{~m}$ wide and $20 \mathrm{~m}$ high as well as a decline of about $10 \mathrm{~m}$ long. The width of the gallery and of the site is considered constant and equal to $1 \mathrm{~m}$.

Halfway in the gallery is a first shaft to access the stope. This shaft is considered closed in the mine's model and is only used to supply fresh air from outside. The end of the wooden ventilation pipe is modeled with an internal diameter of $6 \mathrm{~cm}$, extrapolated based on the fitting found during the excavations. This pipe constitutes one of the air inlets of the model. At the end of the gallery is a decline through which the air circulating and rising from the stope is evacuated. At the outlet, the gallery makes a turn, which differs from the real access to the gallery but facilitates the numerical simulation of the natural convection flow by simplifying the outlet pressure condition and limiting reverse flows. This numerical setup does not disturb the resolution of the flow in the rest of the study area because reverse flows at the outlet are determined by the flow dynamics in the stope.

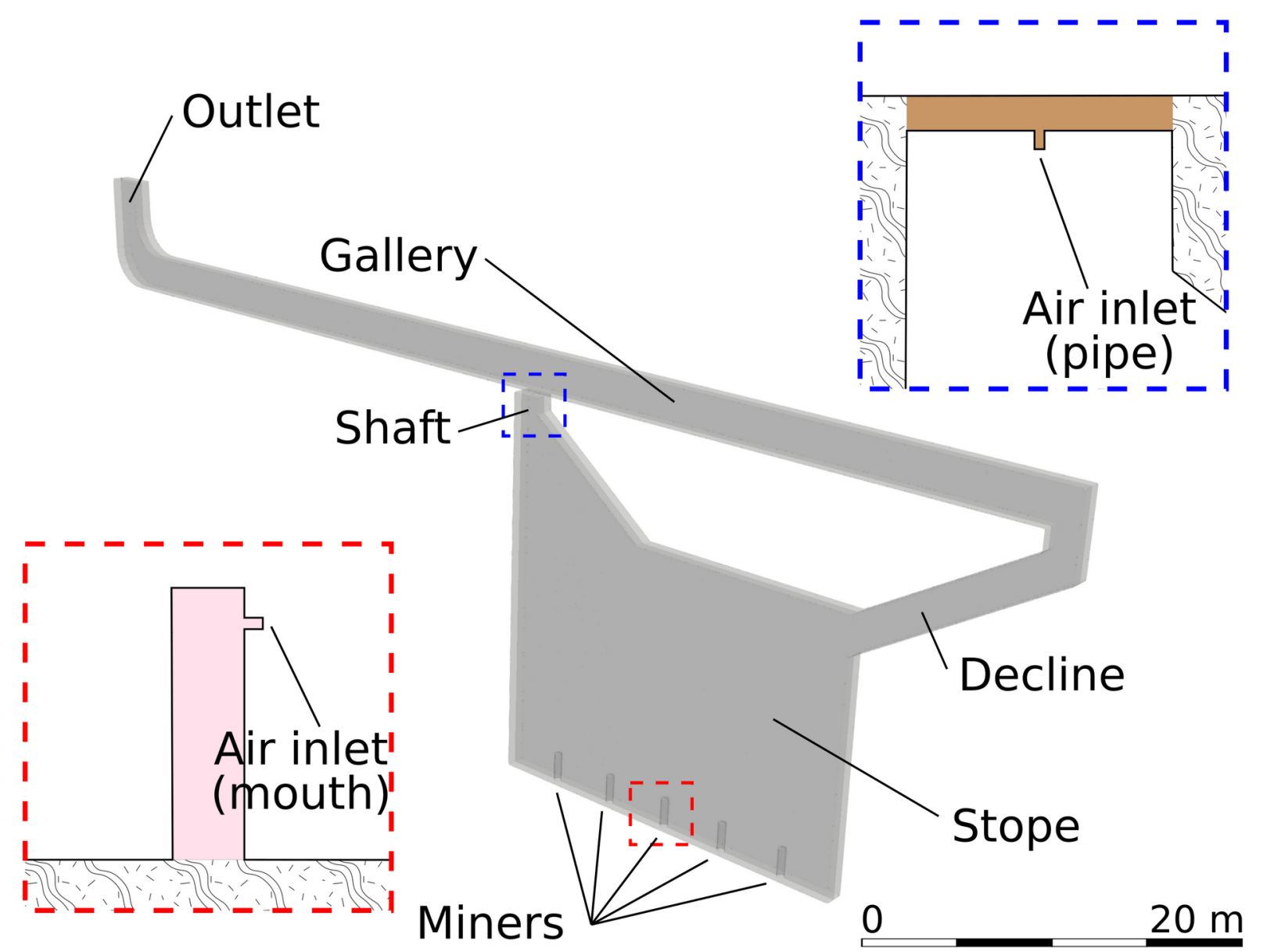

Figure 4: General view of the computational domain. The domain features a gallery and a stope. Five miners are modeled at the bottom of the stope and are numbered from 1 to 5 along ascending $x$ axis. 
2) In order to simulate the production of heat and $\mathrm{CO}_{2}$ in the gallery, one must also model the miners at work. There are five miners modeled and each one is represented by a vertical cylinder $1.5 \mathrm{~m}$ high and $0.4 \mathrm{~m}$ in diameter. The dimensions of this simplified representation permit a heat exchange surface close to that of a real human. For each miner, a second horizontal cylinder, which is $6 \mathrm{~cm}$ in diameter, represents the nose and mouth in order to model the miners' breathing. These horizontal cylinders are five more inlets in the model.

3) Although a minimum of scaffolding may have existed to ease the miners' mobility within the mine, it could also have played a central role in ventilation by channeling the air flow. Hence, numerical simulation must allow for the testing of several gallery layouts: with and without ventilation, but also with and without scaffolding. The chicane shaped scaffolding, which is shown on figure 5 , is designed to facilitate the movement of miners and ventilation in the stope. The height between scaffolding floors is $3 \mathrm{~m}$ and the width of the circulation spaces at the ends of the scaffolding is $1.5 \mathrm{~m}$. In the model, the scaffolding is considered airtight. When there is scaffolding in the stope, the five miners are randomly placed on the different floors.

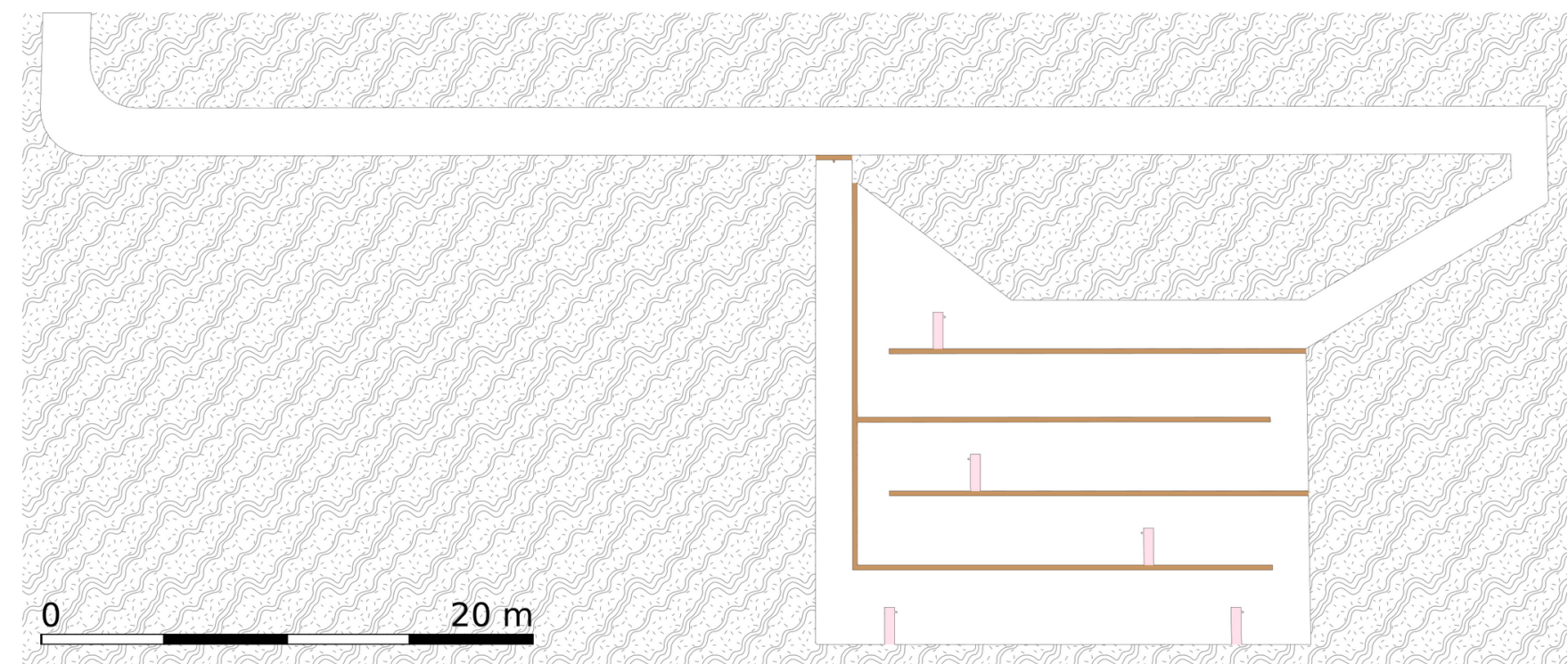

Figure 5: Symmetry plane of the computational domain including scaffolding. The height between scaffolding floors is $3 \mathrm{~m}$ and the width of traffic spaces at the scaffolding ends is $1.5 \mathrm{~m}$. Five miners are placed randomly and numbered from 1 to 5 along the circuit formed by the scaffolding, from bottom to top.

\subsubsection{Model mesh}

Meshing the mine consists in dividing its geometry into elementary volumes small enough to be able to approximate the equations of fluid mechanics in a system of appropriate matrix equations. The aim is to find a compromise between elementary volumes small enough to correctly represent the flow and a limited number of elementary volumes for the given geometry to ensure computational efficiency. 
For the two models, whether there is scaffolding or not, the characteristics of the mesh are the same. Most of the mesh is based on cubic volumes of approximately $5 \mathrm{~cm}$ per side. The mesh is refined around the miners to match the geometry, with elementary volumes of about $8 \mathrm{~mm}$ per side. Along the walls, a layer of thinner volumes is applied to take the friction of the flow into account. The mesh cells' height on the walls of the mine is about $1.5 \mathrm{~cm}$ and $2 \mathrm{~mm}$ on the surface of the miners. The mesh and its refined areas are illustrated in figure 6 and its characteristics are summarized in table 1.

\begin{tabular}{|l|c|}
\hline Cell size in the mine & $5 \mathrm{~cm}$ \\
\hline Cell height along mine walls & $1,5 \mathrm{~cm}$ \\
\hline Cell size around miners & $8 \mathrm{~mm}$ \\
\hline Cell height along miner surface & $2 \mathrm{~mm}$ \\
\hline Total cell number without scaffolding & 2678809 \\
\hline Total cell number with scaffolding & 2650411 \\
\hline
\end{tabular}

Table 1: The mesh features

The mesh is generated using blockMesh and snappyHexMesh utilities from the openFoam toolbox. 




Figure 6: Views of the mesh in the symmetry plane of the domain. The mesh is refined around the miners and on the mine walls to correctly predict the convection heat transfers.

\subsubsection{Boundary conditions}

Once the computational domain is defined and meshed, one more step to undertake in order to solve fluid mechanics equations is to specify initial and boundary conditions. The initial conditions serve as a starting point for the simulation. As for the boundary conditions, they set physical quantities on the domain's borders. There are different kinds of boundary conditions:

- on the mine walls, the temperature is imposed and the flow velocity is zero;

- at the air inlets (the miners' mouths and the exit of the pipe), an air flow is imposed;

- at the gallery outlet, a pressure is imposed.

The boundary conditions are necessary for solving the equations but modifying them also allows to study several ventilation hypotheses. Let us simulate four possible cases of gallery ventilation:

- case 1: without scaffolding, the ventilation being ensured by natural convection and the miners' breath 
- case 2: without scaffolding, the ventilation being forced with an inlet air flow from the pipe;

- case 3: with scaffolding, the ventilation being ensured by natural convection and the miners' breath;

- case 4: with scaffolding, the ventilation being forced by an air flow inlet from the pipe.

\section{Case 1: heat and breathing of the miners}

In this first case, the air flow is caused by two phenomena: a) the natural convection due to the dissipation of heat by the miners at work and b) the miners' breathing. Each miner is considered to dissipate $200 \mathrm{~W}$ of heat while working and his breathing corresponds to an air flow of $15 \mathrm{l} / \mathrm{min}$ $(0.25 \mathrm{l} / \mathrm{s})$. In both cases, this is approximately twice the heat dissipation and respiratory ventilation of a human at rest (Florsch et al., 2002).

The mine gallery walls are set to $10{ }^{\circ} \mathrm{C}$. The pressure at the outlet is equal to one atmospheric pressure of $101325 \mathrm{~Pa}$.

\section{Case 2: forced ventilation}

In the second case, forced ventilation from the pipe is added to the natural convection and breathing of the miners. Let us consider a constant ventilation flow of $13 \mathrm{l} / \mathrm{s}$. This flow corresponds to bellow flow values measured in experimental archaeology (Gauthier and al., 2019). A constant flow also means that the ventilation is continuous. A double bellow system is required, which is equipment frequently shown in De Re Metallica, in particular on the engravings relating to ventilation.

\section{Cases 3 and 4: scaffolding}

The third and fourth cases aim to test the impact of the scaffolding on the ventilation. The modifications made concern the geometry of the domain described above. The boundary conditions of the flow, pressure and temperature are the same as in case 1 and case 2 respectively.

\subsubsection{Numerical methods for solving fluid mechanic's equations}

The criterion to assess the breathability of the air within the mine is the $\mathrm{CO}_{2}$ concentration. In order to simplify the simulations and to improve computational efficiency, flow and $\mathrm{CO}_{2}$ concentration simulations are segregated. First, a stationary simulation solves the flow of the natural convection due to the heat emanating from the miners. Then, a non-stationary simulation predicts how the $\mathrm{CO}_{2}$ spreads over time. These simulations are performed with the Computational Fluid Dynamics (CFD) software OpenFOAM v. 6. (https://www.openfoam.org). 


\section{Flow simulation}

Natural convection flow simulations are performed using the buoyantSimpleFoam solver from the OpenFOAM toolbox that solves the following continuity, momentum and energy equations (Kim, 2020).

Continuity equation:

$$
\nabla \cdot(\rho u)=0
$$

where $u$ and $\rho$ are the velocity vector and density.

Momentum equations:

$$
\nabla \cdot(\rho u u)=-\nabla p+\rho g+\nabla \cdot\left(2 \mu_{e f f} D(u)\right)-\nabla\left(\frac{2}{3} \mu_{e f f}(\nabla \cdot u)\right)
$$

where $\mathrm{p}, \mathrm{g}, \mu_{\mathrm{eff}}$ and $\mathrm{D}(\mathrm{u})$ are the static pressure, gravitational acceleration, effective viscosity and rate of the strain tensor, (with $\mu_{\text {eff }}=\mu+\mu_{t}$ and $D(u)=\frac{1}{2}\left(\nabla u+(\nabla u)^{T}\right)$ ).

\section{Energy equation:}

$$
\nabla \cdot(\rho u h)+\frac{\partial \rho K}{\partial t}+\nabla \cdot(\rho u K)-\frac{\partial p}{\partial t}=\nabla \cdot\left(\alpha_{e f f} \nabla h\right)+\rho u \cdot g
$$

where $\mathrm{K}$ and $\alpha_{\text {eff }}$ are the kinetic energy and effective thermal diffusivity.

The boundary conditions associated to these equations are given in the table below.

\begin{tabular}{|l|l|l|}
\hline Domain location & Momentum equations & Energy equation \\
\hline Pipe inlet & Fixed velocity value & Fixed temperature value \\
\hline Miners inlet & Fixed velocity value & Fixed temperature value \\
\hline Mine outlet & Fixed pressure value & Fixed temperature value \\
\hline Mine walls & No slip & Fixed temperature value \\
\hline Miners & No slip & Fixed heat flux value \\
\hline
\end{tabular}

The flow can be laminar or turbulent and it can be predicted thanks to Reynolds number $(\mathrm{Re})$ and Rayleigh number $(\mathrm{Ra})$ that compare convection forces and viscous forces of the flow for forced convection flow and natural convection flow respectively.

$$
R e=\frac{\rho U D_{h}}{\mu} \quad R a=\frac{\rho \beta \Delta T l^{3} g}{\mu \lambda}
$$


where $D_{h}, \beta, \Delta T, 1, \lambda$ are hydraulic diameter of the pipe, thermal expansion coefficient of air, temperature gradient between the miners and the mine, miner's average height and thermal conductivity of air.

The forced air flow coming from the pipe has a Reynolds number close to 18000 and the flow due to the miner's heat has a Rayleigh number about $10^{10}$. Thus, both flows are turbulent.

To account for turbulence, the flow's simulation is based on « Reynolds-averaged Navier-Stokes (RANS) » equations. The turbulence is represented by the Reynolds Tensor, solved with the k- $\varepsilon$ model derived from a hypothesis of eddy viscosity.

The limitations of these models for natural convection flows are well known (Hanjalić, 2002). However, their versatility and settings convenience, when dealing with a variety of applications, make RANS equations a suitable choice for a first quantitative approach of ventilation problems within medieval mines. Analytical calculations of orders of magnitude for velocity and temperature provide a way to ensure first-order validity of the solution.

The RANS equations are then transformed into a linear system using the Finite Volume Method (FVM) applied to the computational domain mesh. The matrix-form equations are then solved through an iterative process, a variation of the SIMPLE algorithm adapted for buoyancy-driven flows.

\section{CO2 concentration simulation}

Simulations of $\mathrm{CO} 2$ dispersion are performed using scalarTransportFoam solver that solves a transport equation of a passive scalar through a fixed velocity field. Here the passive scalar is $\mathrm{CO}_{2}$ concentration.

$$
\frac{\partial C}{\partial t}+\nabla \cdot(U C)-\nabla^{2}\left(D_{C} C\right)=0
$$

where $\mathrm{C}, \mathrm{D}_{\mathrm{C}}$ are the $\mathrm{CO}_{2}$ concentration and diffusion coefficients divided by the fluid density.

The boundary conditions for this equation are given in the table below.

\begin{tabular}{|l|l|}
\hline Domain location & Transport equation \\
\hline Pipe inlet & Null concentration value \\
\hline Miners inlet & Fixed concentration value \\
\hline Mine outlet & Null concentration gradient value \\
\hline Mine walls & Null concentration gradient value \\
\hline Miners & Null concentration gradient value \\
\hline
\end{tabular}

During the second simulation step, only the $\mathrm{CO}_{2}$ transport equation is solved based on the fixed flow field from the first simulation. The stationary flow field does not take into account the inherent oscillations of large eddies but provides an average solution allowing to calculate the $\mathrm{CO}_{2}$ dispersion. 


\section{Simulations of air flow and heat transfers}

First, we simulate the air flow and the coupled heat transfers of mixed convection, coupling phenomena of natural convection and forced convection. The simulation is stationary, that is to say that the iterative calculation converges towards a stable solution over time. From this solution, we can then extract and analyze the flow structure and the heat transfers at work in the mine.

To achieve a steady flow field, 20,000 iterations are performed. The calculation is parallelized over the 12 threads ( 6 cores) of an Intel Core i7-6800K processor and lasts around 13.5 hours.

\subsection{Velocities of the natural convection flow}

Heat produced by miners at work causes the air around them to heat up. The difference in density between the hot air around the miners and the cold air in the rest of the stope causes an upward flow of air by natural convection. Numerical simulation makes it possible to estimate the velocity of this flow at any point in the calculation domain.


Figure 7: Velocity field in the symmetry plane of the computational domain. The maximum velocity of the natural convection flow is below $1 \mathrm{~m} / \mathrm{s}$ while the air flow velocity at the pipe exit is close to $4 \mathrm{~m} / \mathrm{s}$. The ventilation flow rate is small compared to the natural convection and does not seem to disturb the flow pattern much. The scaffolding constrains the development of natural convection.

The velocity of the upward flow of natural convection is around $0.7 \mathrm{~m} / \mathrm{s}$ in the absence of scaffolding, as shown on figure 7 . The velocity is slightly lower when there is scaffolding because it constrains the upward flow. 


\subsection{Heat transfers and validation of the natural convection flow}

When considering natural convection, the air flow and heat transfers are strongly coupled. The temperature then provides a criterion for validating the resolution of the flow in comparison with theoretical calculations. Under ideal natural convection conditions (an object heating up in an infinite space filled with an ideal gas), it is possible to estimate the ascending flow velocity from the temperature and the geometry of the object (Lismonde, 2002).

Based on these considerations, we have the following equation:

$$
\begin{aligned}
V \approx \sqrt{g L \frac{\Delta T}{T}} \text { with } & g: \text { gravity acceleration } \\
L & : \text { object height } \\
& \Delta T / T: \text { relative difference of temperature between surrounding and the object }
\end{aligned}
$$

By reversing this relationship, the average temperature of the heating object can be estimated from the velocity of the flow. Here the velocity of the upward flow is $0.7 \mathrm{~m} / \mathrm{s}$, which corresponds to an average miner surface temperature of $20^{\circ} \mathrm{C}$.

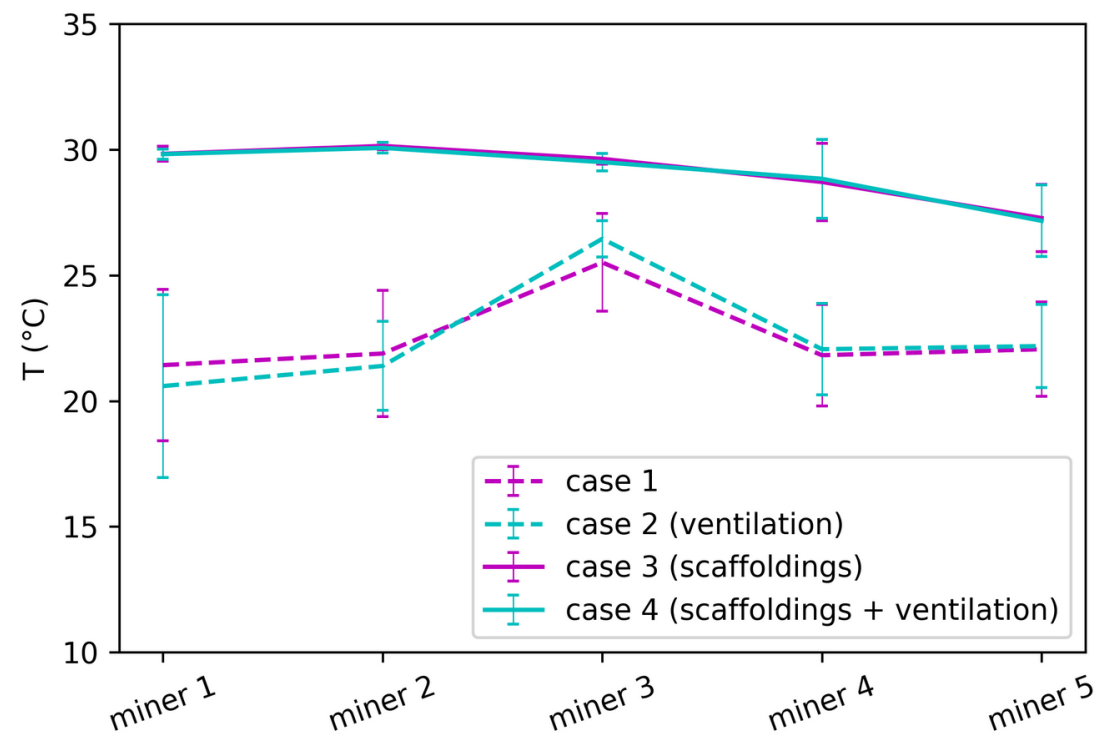

Figure 8: Miners' average surface temperatures. Without scaffolding, it appears that miner 3, in the middle, dissipates heat less efficiently. The scaffolding constrains natural convection and stabilizes temperatures. In this case, miner 5 dissipates heat better because the flow has more space above him.

Figure 8 shows that the average surface temperature of the miners, computed by the simulation, is around $24{ }^{\circ} \mathrm{C}$ without scaffolding and around $29{ }^{\circ} \mathrm{C}$ with scaffolding. These temperatures are higher than the estimate of $20^{\circ} \mathrm{C}$ valid for ideal natural convection. The walls of the stope and the scaffolding 
limit the development of natural convection cells and reduce the flow velocity for a given temperature gradient. Nevertheless, the simulation results are still quite close to the theoretical estimates.

\subsection{Flow structure}

Due to the natural convection, the spreading of the $\mathrm{CO}_{2}$ exhaled by the miners depends on the velocity of the flow, but also on its structure. A linear air flow in a pipe leads to the transport of matter in a direction whereas a rotational flow can translate an exchange of momentum without exchange of matter. To analyze the structure of a flow, it is useful to represent the velocity field on a logarithmic scale. In order to compare the flow from one case to another, a similar scale is used for all simulations and the corresponding figures $9,10,11$ and 12 .

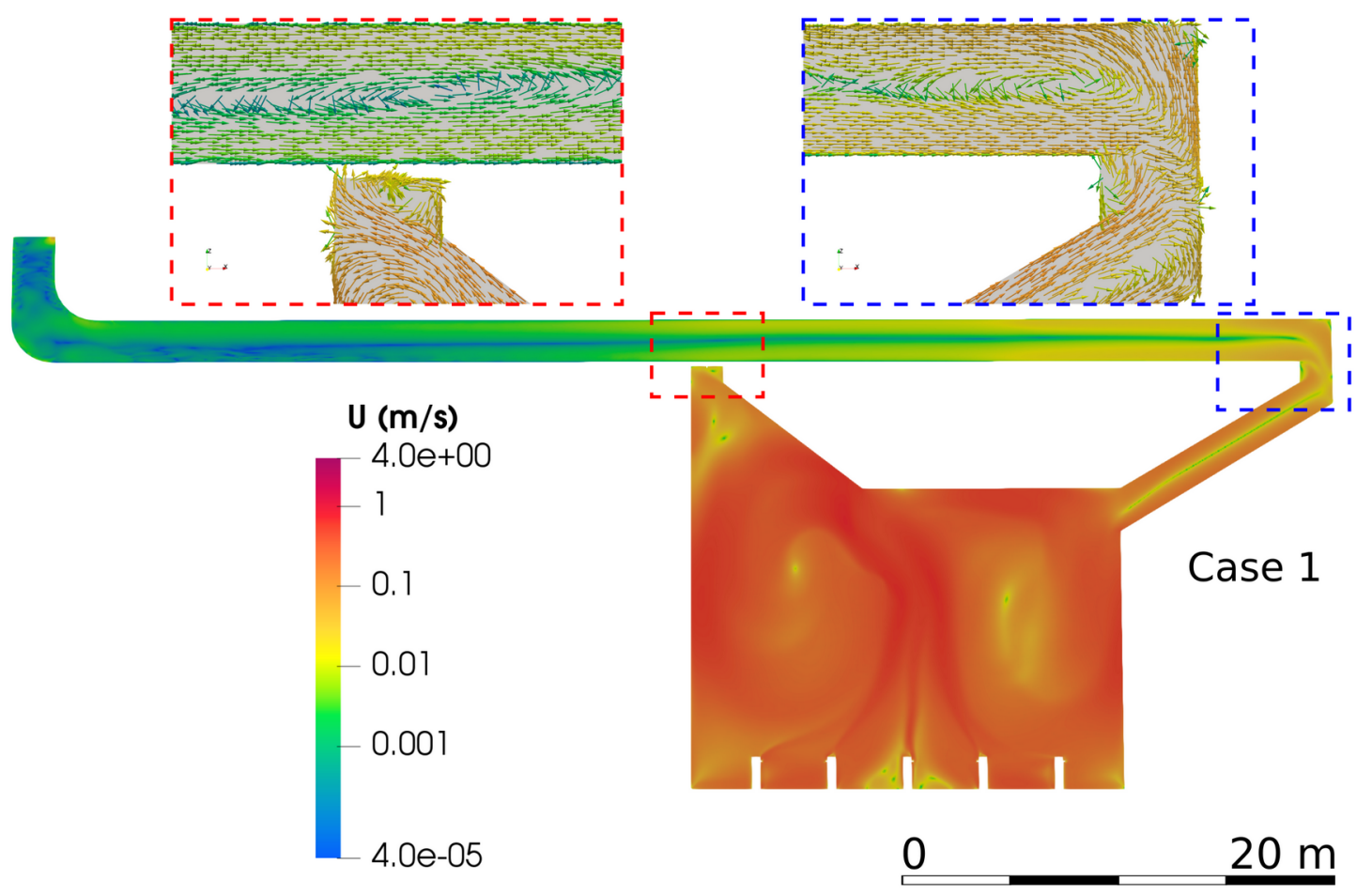

Figure 9: Velocity field (log scale) in the symmetry plane for case 1; zoom on velocity vectors. The natural convection creates two main convection cells in the stope. Two secondary elongate eddies appear in the decline and the gallery, showing much lower velocities. The velocity vectors indicated in red highlight the rotational structure of the flow in the gallery. The velocity vectors indicated in blue show the flow discontinuity between two secondary eddies. 




Figure 10: Velocity field (log scale) in the symmetry plane for case 2; zoom on velocity vectors. The forced ventilation does not disturb the main convection cells much. However, the eddy in the gallery is disturbed by an outflow (red). A flow continuity is established between two secondary eddies (blue).



Figure 11: Velocity field (log scale) in the symmetry plane for case 3; zoom on velocity vectors. Natural convection cells develop on each floor with a miner. Again the vector field indicated in blue shows mostly momentum exchanges between eddies. The flow velocity is very small in the gallery (red) which makes it difficult to properly solve the flow field. 


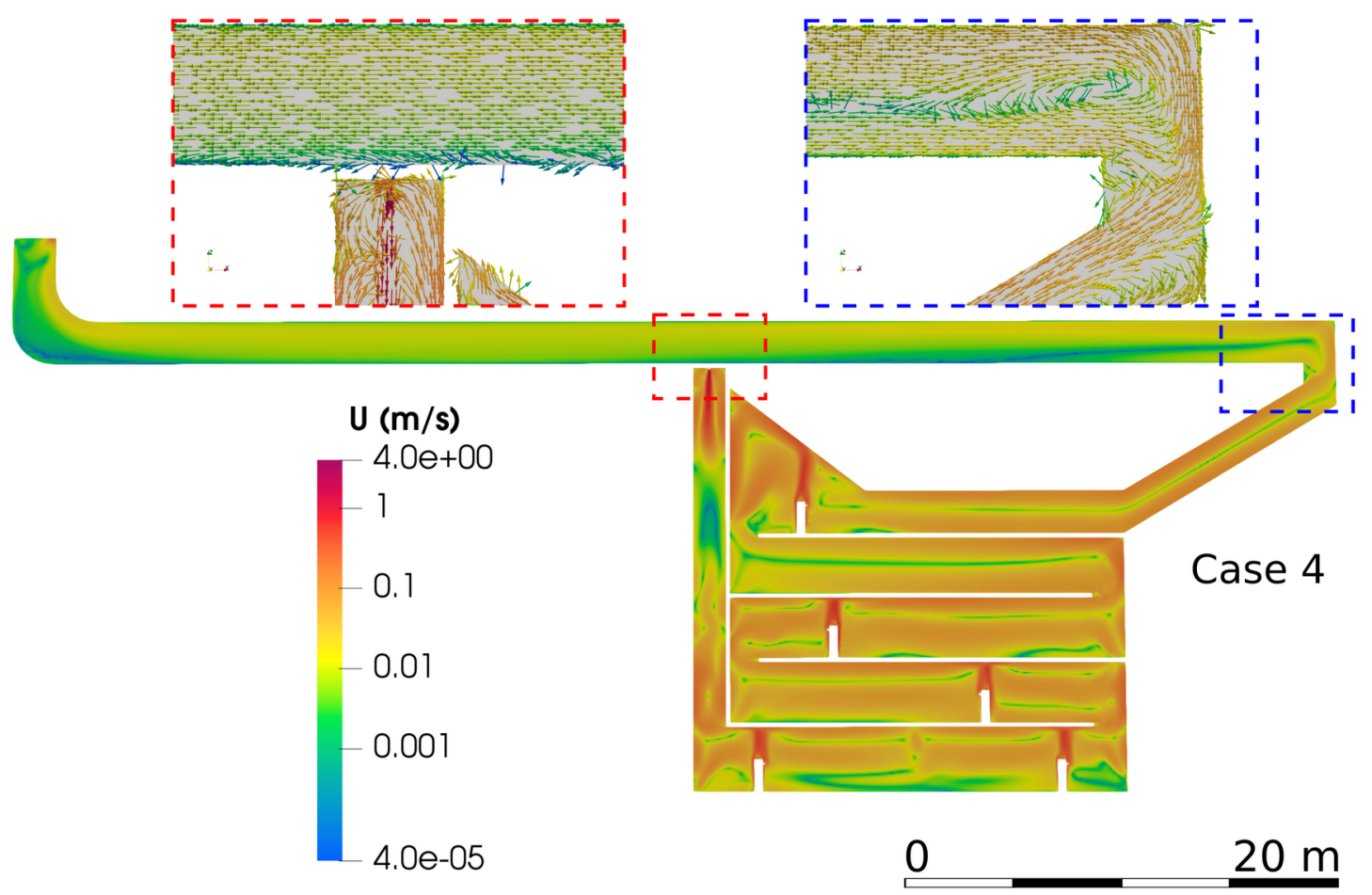

Figure 12: Velocity field (log scale) in the symmetry plane for case 4; zoom on velocity vectors. The forced ventilation does not disturb the convection cells around miners much. However, a flow continuity is established between two secondary eddies (blue). A fully developed outflow is established in the gallery (red).

In short, the addition of ventilation does little to disrupt the flow structure in the stope but establishes a flow continuity between the eddies from the site to the exit of the gallery. This phenomenon is verified with and without the scaffolding.

\subsection{Simulations of $\mathrm{CO}_{2}$ concentration}

Simulations of the $\mathrm{CO}_{2}$ concentration are non-stationary simulations. The aim here is to simulate $\mathrm{CO}_{2}$ spreading in the mine over 24 hours. The velocity fields from previous simulations serve as "matrices" for propagation by advection or diffusion.

The time-step of the simulation is set to $10 \mathrm{~s}$ which means that 8,640 time-steps are solved. The calculation, equally parallelized over the 12 threads (6 cores) of an Intel Core $17-6800 \mathrm{~K}$ processor lasts around 2.5 hours.

\subsubsection{Geometry, mesh and boundary conditions}

The geometries and meshes used are the same as for the previous simulations. Specific boundary conditions define the $\mathrm{CO}_{2}$ concentration of the flows entering the computational domain. Air exhaled by miners has a $\mathrm{CO}_{2}$ concentration of $5 \%$ while the air from the ventilation duct has a $\mathrm{CO}_{2}$ concentration equal to zero. 


\subsection{2 $\mathrm{CO}_{2}$ concentration}

The $\mathrm{CO}_{2}$ flow rate is the product of $\mathrm{CO}_{2}$ concentration and air flow rates exhaled by miners, i.e. $0.0625 \mathrm{l} / \mathrm{s}$ for the five miners. After 24 hours, $5.4 \mathrm{~m}^{3}$ of $\mathrm{CO}_{2}$ entered the $456 \mathrm{~m}^{3}$ volume of the underground model. This corresponds to a theoretical maximum average concentration of $1.18 \%$. During the simulation, the average concentration of $\mathrm{CO}_{2}$ is calculated at all times. One can then plot the evolution of this concentration as a function of time, as shown on figure 13 for all four calculated cases.

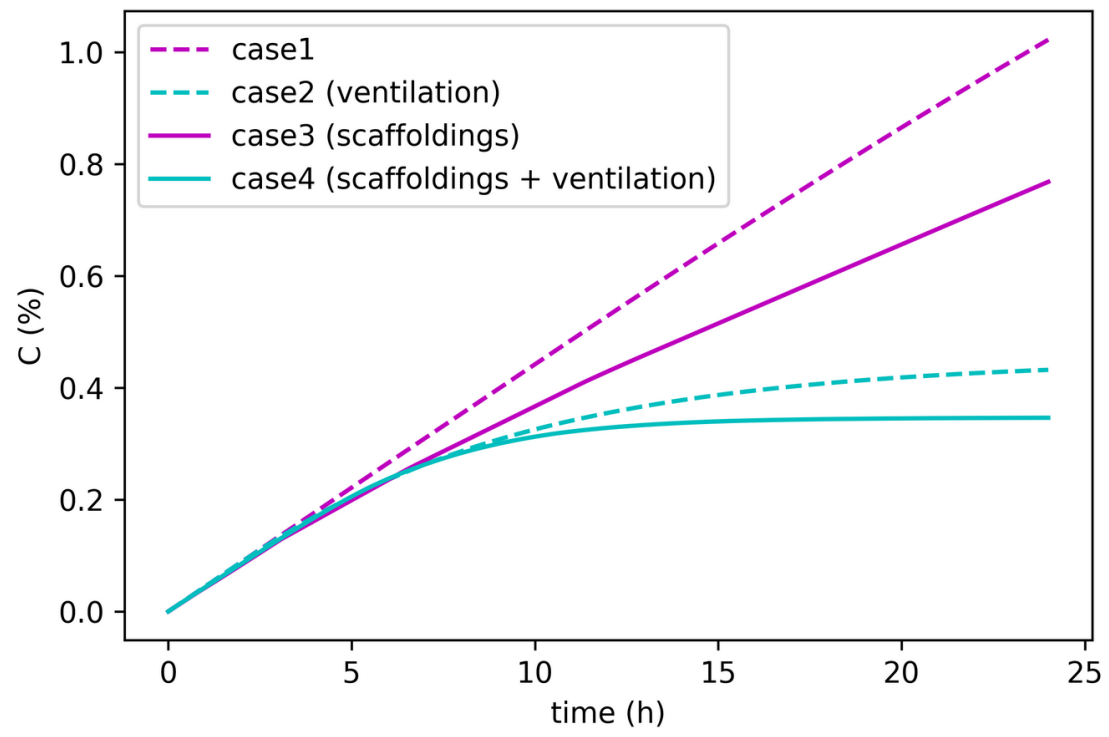

Figure 13: Average $\mathrm{CO}_{2}$ concentration in the mine. Without forced ventilation, the average $\mathrm{CO}_{2}$ concentration is close to $1 \%$ after a $24 \mathrm{~h}$ work shift of the five miners. The forced ventilation stabilizes the $\mathrm{CO}_{2}$ concentration in the mine below $0.5 \%$. The stabilization is reached faster in case 4, with scaffolding. 


\section{Case 1}
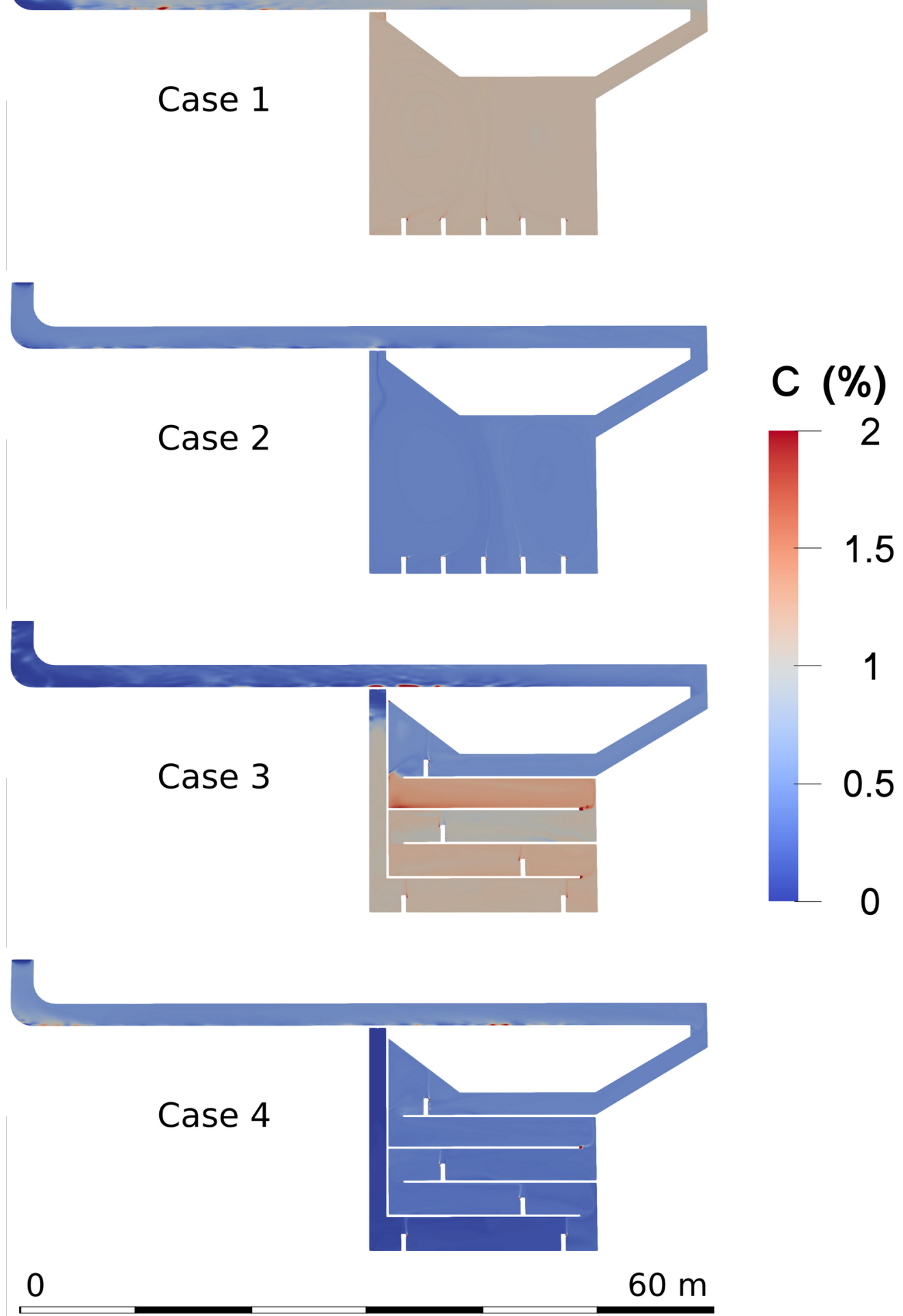

Figure 14: $\mathrm{CO}_{2}$ concentration field on the symmetry plane of the domain, after $24 \mathrm{~h}$. The $\mathrm{CO}_{2}$ concentration field is uniform without scaffolding whereas stagnation appears with scaffolding in case 3. The forced ventilation decreases the $\mathrm{CO}_{2}$ concentration inside the mine after $24 \mathrm{~h}$. 
Figure 13 shows the evolution of the average $\mathrm{CO}_{2}$ concentration over time. In case 1, without scaffolding or forced ventilation, the average $\mathrm{CO}_{2}$ concentration in the mine reaches $1 \%$ after $24 \mathrm{~h}$, which is very close to the theoretical maximum average concentration calculated above. The constant increase in concentration confirms that only a tiny part of the exhaled $\mathrm{CO}_{2}$ escapes from the mining site through the gallery. The addition of the scaffolding in the stope for case 3 slightly improves the evacuation of $\mathrm{CO}_{2}$ but the average concentration remains high and is still increasing after $24 \mathrm{~h}$. The forced ventilation in cases 2 and 4 slows the increase in average concentration which also seems to stabilize.

The $\mathrm{CO}_{2}$ concentration fields displayed in figure 14 are very homogeneous in the absence of scaffolding since the natural convection causes the mixing of air. However, the average concentration is much higher in case 1 than in case 2 (which includes forced ventilation). In case 1, the spreading of $\mathrm{CO}_{2}$ relies only on diffusion, while in case 2 convection of $\mathrm{CO}_{2}$ occurs thanks to the forced ventilation. In case 1 and 3, flow velocity in the gallery is very low which hinders the evacuation of $\mathrm{CO}_{2}$. In case 3 , the scaffolding prevents advection by multiplying the number of convection cells and finally causes the stagnation of $\mathrm{CO}_{2}$ in the lower part of the stope. The $\mathrm{CO}_{2}$ concentration approaches $2 \%$ on some floors, a local concentration much higher than the average concentration of $\mathrm{CO}_{2}$ in the whole mine.

\section{Discussion}

The concentration of $\mathrm{CO}_{2}$ in the air is considered dangerous from $1 \%$ up, with a risk of respiratory acidosis (ANSES, 2013). The results of the simulations establish that such a concentration average is reached over the entire underground in 24 hours. Analysis of the structure of the flow shows that in the absence of ventilation, there is little exchange of matter between flow eddies and the rest of the air. Natural convection alone does not permit air renewal and keeps stale air confined in the stope.

Stagnation would also cause the accumulation of $\mathrm{CO}_{2}$ day by day within the underground extraction site. By imagining a two eights work day (Agricola, 1556; Degermann, n.d.), the $\mathrm{CO}_{2}$ concentration can be extrapolated after one day and a half and is then equivalent to the $\mathrm{CO}_{2}$ concentration at the end of the simulations for cases 1 and 3.

On the other hand, ventilation ensures a good evacuation of $\mathrm{CO}_{2}$, as shown by the analysis of the structure of the flow. The $\mathrm{CO}_{2}$ is no longer trapped in the convection cells but also spreads by advection from one eddy to another, from the stope to the exit of the gallery. The average concentration of $\mathrm{CO}_{2}$ stabilizes and capped to a sustainable level.

Regarding the organization of underground works, the results of numerical simulations show that scaffolding and forced ventilation are a valid solution to breathability problems in stopes that do not have two accesses located at different altitudes. It must be said that the scaffolding's first aim is not to enhance ventilation, and it can be noted that the $\mathrm{CO}_{2}$ rate is low enough in case 2 to enable the miners' 
work. In any case, scaffolding is usually required to work within a stope. Forced ventilation is needed all the more, and scaffolding must be considered a part of the ventilation system.

The excavation of the Giro mine thus sheds light on the use of forced ventilation thanks to the duct remains found between the entrance and the deep stope, originally used to convey air. These remains are the only evidence for the potential existence of such a system. The traces left by this equipment are usually scarce or lacking. The presence of scaffolding, of which main purpose is to ease both circulation and access of miners in a stope, does not necessarily attest to a ventilation system on its own.

So far archaeologists have not really considered the hypothesis of forced air circulation, let alone its implementation in remote stopes. This can be explained by the numerous traces of false ceiling and ventilation shafts that have been observed, e.g. in Sainte-Marie-aux-Mines. The morphology of a mine is in constant evolution until its abandonment. In many cases, ventilation systems are dropped once a gallery exits at another altitude. Hence, the good conservation of remains of forced ventilation facilities that are no longer necessary during the main exploitation period of the mine is unlikely. In any case, reflections about ventilation must be based on the underground galleries and stopes morphology and their evolution. Unfortunately, the parts of any ancient mine that were most typically concerned by a need of fresh air supply and could provide more evidence of forced ventilation system are under the valley level, and thus flooded.

\section{Conclusion}

Numerical simulations show that the $\mathrm{CO}_{2}$ production of five miners at work can quickly render the air unbreathable in the stope of a mine such as Giro mine. The natural convection produced by the heat dissipation of the miners does not allow the $\mathrm{CO}_{2}$ to be evacuated. An outdoor ventilation system seems required. A wooden pipe with a diameter corresponding to the metal fitting found during the excavations of the gallery, supplied by a double bellow system, allows sufficient ventilation of the work area. The setting up of scaffolding in the stope facilitates the movement of miners and promotes ventilation.

Numerical simulations of the air flow in the mine gallery and the propagation of the resulting $\mathrm{CO}_{2}$ provide quantitative elements to assess the quality of the gallery ventilation relative to several hypotheses. This validates technical assumptions derived from archaeological data. In the case of Giro

mine, numerical simulation replaces conventional experimentation that is not feasible in the context of experimental archaeology. 


\section{Acknowledgments}

We sincerely thank the Association Spéléologique pour l'Etude et la Protection des Anciennes Mines (ASEPAM) in Sainte-Marie-aux-Mines, the owners of the mine Brigitta Wolf and Roger Zenner, and the Giro mine excavation team, especially Antonin Hergault, Margaux Herbrich and Paul Winterhalter.

We are grateful to Pauline Florsch for the numerous improvements of the English.

We would like to thank the two reviewers who were of great help in improving the paper.

\section{Funding}

ERDF (European Regional Development Funds): Interreg Regio Mineralia

DRAC Grand Est (French Ministère de la Culture)

\section{References}

Agricola, G.,1556. De Re Metallica, Froben, Basel.

ANSES, 2013. Concentrations de $\mathrm{CO}_{2}$ dans l'air intérieur et effets sur la santé, édition scientifique ANSES, Maisons-Alfort.

Bonnamour, G. and Marconnet, Chr., 2014. « Ouvrage d'assistance et espace minier en contexte mellois : fouille préventive du site du Prieuré (Saint-Martin-Les-Melle, 79) », in Du monde franc aux califats omeyyade et abbasside : extraction et produits des mines d'argent de Melle et de Jabali, Deutsches Bergbau-Museum, Bochum, p. 77-91.

Degermann, J., n.d.. « Réglement sur les mines du 22 juillet 1527 (Sainte-Marie-aux-Mines) », archives municipales de Sainte-Marie-auxMines, Degermann 3497(2).

Florsch, N. and ASEPAM, 1995. «Etude quantitative de l'aérage d'une galerie de mine du XVI siècle », in Revue d'Archéométrie, 19, p. 5-18.

Florsch, N., Beghein, C., Lismonde, B., Clerc, P., 2002. « Sur l'aérage naturel des anciennes galeries de mines en zone montagneuse : expérimentation et modélisation », in Revue d'Archéométrie, 26, p. 47 55.

Gauthier, J., Fluck, P., Disser, A., Château, C., 2015. "The Alsatian Altenberg: a seven-hundred-year laboratory for silver metallurgy", dans Hauptmann, A., Modarressi-Tehrani, D. (ed.), Archaeometallurgy in Europe III, Der Anschnitt, Beiheft 26, Deutsches Bergbau-Museum, Bochum, p. 271-278.

Gauthier, J., Flament, J., Silenzi, Fr., Téreygeol, Fl., 2019. « Broyer le minerai et affiner l'argent à Castel-Minier : deux exemples d'une approche intégrée de l'expérimentation », dans Verly, G., 
Rademakers, Fr. W., Téreygeol, Fl. (dir.), Studies in Experimental Archaeometallurgy. Methodological approaches from non ferrous metallurgies, éditions Mergoil, Drémil Lafage, p. 4355 .

Gauthier, J. and Hergault, A., 2019. « La mine Giro, massif de l'Altenberg, Sainte-Marie-aux-Mines », in Gauthier, J. (dir.), Mines et métallurgie des métaux non-ferreux en Alsace du haut Moyen Âge au XVII siècle, rapport de Projet Collectif de Recherches, SRA Alsace, p. 11-47.

Grandemange, J., 1992. "L'aérage dans les mines polymétalliques du massif vosgien au XVI ${ }^{e}$ siècle », in Les techniques minières de l'Antiquité au XVIII $I^{e}$ siècle, $113^{e}$ Congrès National des Sociétés Savantes, Strasbourg, p. 407-420.

Hanjalić, K., 2002. "One-Point Closure Models for Buoyancy-Driven Turbulent Flows", in Annual Review of Fluid Mechanics, 34, p. 321-348.

Kim, D. and Kim J., 2020. "Simulation of a conjugate heat transfer using a preCICE coupling library", in Transactions of the Korean nuclear society virtual spring meeting, July 9-10, 2020.

Lismonde, B., 2002. Aérologie des systèmes karstiques, CDS Isère, Grenoble.

Téreygeol, Fl., 2014. "À la main ou au feu : les choix techniques pour l'extraction des minerais argentifères " in Du monde franc aux califats omeyyade et abbasside : extraction et produits des mines d'argent de Melle et de Jabali, Deutsches Bergbau-Museum, Bochum, p. 55-76. 